\title{
RESISTÊNCIA A COMPRESSÃO EM TESTEMUNHO DE CONCRETO: INFLUÊNCIA DO FATOR DE ESBELTEZ, DIÂMETRO DA AMOSTRA E MÉTODO DE EXTRAÇÃO
}

\section{Compressive strength in concrete cores extracted: influence of slenderness ratio, specimen diameter and extraction method}

\author{
Marcelo Henrique Farias de Medeiros' , Ana Paula Brandão Capraro², \\ Giovana Costa Réus ${ }^{3}$, Marcel Luiz Escobedo ${ }^{4}$
}

Recebido em 02 de junho de 2016; recebido para revisão em 11 de agosto de 2016; aceito em 28 de setembro de 2016; disponivel on-line em 29 de março de 2017.

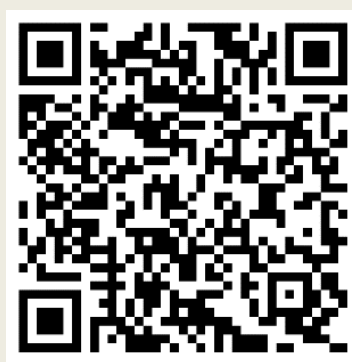

PALAVRAS CHAVE:

Extração de testemunhos; Concreto;

Resistência à compressão axial.

\section{KEYWORDS:}

Concrete cores extracted; Concrete;

Axial compressive strength.
RESUMO: Este trabalho tem como objetivo avaliar a influência dos fatores de forma nos ensaios de resistência à compressão em testemunhos de concreto. Para isso foram moldadas e extraídas amostras de concreto de 20 e $30 \mathrm{MPa}$. Variou-se o diâmetro da base das amostras (50 e 100mm) e sua esbeltez (de 1 a 3). Para verificar a diferença entre amostras moldadas e extraídas, no momento da fabricação do concreto foram moldados corpos de prova de $100 \times 200 \mathrm{~mm}$ e dois blocos de $500 \times 630 \times 270 \mathrm{~mm}$ de onde os testemunhos foram extraídos. Os dados indicam que os valores de resistência à compressão obtidos em testemunhos de $50 \mathrm{~mm}$ de diâmetro tenderam a ser mais baixos do que os obtidos com $100 \mathrm{~mm}$. A magnitude desta diferença é afetada pelo nível de resistência do concreto avaliado. Além disso, a resistência dos testemunhos extraídos foi menor ou igual à obtida em corpos de prova moldados, mesmo mantendo as condições de cura constantes entre o bloco e os corpos de prova normalizados. Dessa forma, o que pode ser concluído neste estudo é que, a resistência real da estrutura é minorada pelo procedimento da extração, sendo este influenciado por diversos fatores. Dentre as possíveis variáveis da extração, o diâmetro foi um fator que demonstrou influência significativa na propriedade do material ensaiado

ABSTRACT: This study aims to evaluate the influence of shape ratio in compressive strength tests. Concrete specimens with 20 and $30 \mathrm{MPa}$ was made and extracted. The diameter of the specimen's base was 50 and $100 \mathrm{~mm}$ and its slenderness ratio vary 1 to 3 . To verify the difference between molded and samples taken at the time of manufacture of concrete molded bodies were evidence of $100 \times 200 \mathrm{~mm}$ and two blocks of $500 \times 630 \times 270 \mathrm{~mm}$ where witnesses were extracted. The results indicated that the axial compressive strength values obtained with concrete cores extracted of $50 \mathrm{~mm}$ diameter tended to be lower than those obtained with $100 \mathrm{~mm}$, and the magnitude of this difference is affected by the resistance level of the evaluated concrete. Furthermore, the resistance of concrete cores extracted was less than or equal to the obtained in the molded test specimens, while maintaining constant the curing conditions between the block and standard specimens. Thus, it can be concluded in this study is that the real strength of the structure is alleviated by the extraction procedure, which is influenced by several factors. Among the possible variables of extraction, the diameter was a factor that showed a significant influence on the property of the material tested.

* Contato com os autores:

${ }^{1}$ e-mail: medeiros.ufpr@gmail.com (M. H. F. Medeiros)

Eng. Civil, Professor Doutor do Curso de Engenharia Civil, da Universidade Federal do Paraná.

${ }^{2}$ e-mail: anapcapraro@gmail.com (A. P. B. Capraro)

Enga. Civil, Mestranda do Programa de Pós-Graduação em Engenharia Civil da Universidade Federal do Paraná

3 e-mail: gio_reus@yahoo.com.br (G.C. Réus)

Enga. Civil, Mestranda do Programa de Pós-Graduação em Engenharia Civil da Universidade Federal do Paraná.

${ }^{4}$ e-mail: marcel.escobedo@lactec.org.br (M. L. Escobedo)

Eng. Civil, Pesquisador do Instituto Tecnológico para o Desenvolvimento. 


\section{INTRODUÇÃO}

Dentre vários métodos utilizados para a avaliação de resistência do concreto de uma estrutura, o ensaio de compressão em corpos de prova cilíndricos (NBR 5739 - ABNT, 2007), realizado em testemunhos extraídos, é reconhecidamente o mais confiável e preciso entre os métodos de inspeção (ACl 214.4R-10/2010 e BS 6089/2010). No Brasil, o processo de extração é normalizado pela NBR 7680-1 (ABNT, 2015), servindo para avaliar se o concreto lançado adequa-se a resistência de aceitação dos ensaios normalizados (NBR 12655 - ABNT, 2015).

Desse modo, a extração de testemunhos de estruturas acabadas é feita quando há dúvidas quanto à resistência e o desempenho do concreto lançado, seja por resultados de ensaios laboratoriais com valores abaixo do esperado, durante o controle tecnológico, ou por sinais de deterioração do concreto, ao longo de sua vida útil. Em muitos casos a adoção deste método se dá sob disputa judicial, decorrente da não conformidade de lotes de controle $\left(f_{c k, e s t}<f_{c k}\right)$, de acordo com a NBR 12655 (ABNT, 2015), utilizando-se do ensaio de compressão axial para averiguar qual o valor de resistência do concreto efetivo na obra (NEVILLE, 2008), a partir de um método normalizado de moldagem (NBR 5738 - ABNT, 2015) e ruptura (NBR 5739 - ABNT, 2007). Nesses casos, a NBR 6118 (ABNT, 2014) recomenda a verificação da resistência do concreto in loco, por meio de testemunhos (NBR 7680-1 - ABNT, 2015), balizada pelas diretrizes da NBR 12655 (ABNT, 2015).

A extração de testemunhos pode ser utilizada também para analisar o estado atual de uma estrutura e sua durabilidade, sendo que: (1) as amostras obtidas podem ser objetos de análises em laboratório para determinação da qualidade do concreto; (2) é possível determinar a profundidade da frente de carbonatação em testemunhos extraídos; (3) determinar o teor de cloretos; (4) diagnosticar a expansão decorrente de reações álcali-agregado (RAA); (5) e determinar propriedades físicas e mecânicas como a densidade, absorção de água, resistência à tração, entre outras. Exemplos de pesquisas nesta área de inspeção empregando a extração de testemunhos são os de Medeiros et al. (2013) e Hoppe Filho et al. (2014), o primeiro focado em um trabalho de inspeção em uma edificação próxima ao mar, no Rio de Janeiro, Brasil, e o segundo focado em uma inspeção para mensurar o grau de degradação do concreto de uma estação de tratamento de esgoto (ETE) na cidade de Curitiba, Paraná, Brasil

Embora o ensaio de resistência à compressão, baseada em corpos de prova extraídos, seja um processo simples de realizar, os resultados obtidos podem apresentar consideráveis em função da variedade de parâmetros condicionantes (forma e tamanho da amostra, o diâmetro do testemunho, a relação altura/diâmetro, a umidade da amostra durante o ensaio, o diâmetro máximo característico dos agregados, o tipo da máquina extratora, os danos sofridos pelos testemunhos durante o processo de extração, o método de compactação/adensamento durante o lançamento e as condições e histórico de cura da estrutura, a idade da extração, a planicidade das superfícies em contato com as placas da máquina de ensaio, a taxa de carregamento, etc.) (Helene, 1984; Castro, 2009; Vieira Filho, 2007).

A definição da resistência real do concreto dentro de um elemento está relacionada a um método de ensaio específico, que seja capaz de fazer com que a resistência obtida dos testemunhos extraídos aproxime-se da resistência do concreto, efetivamente lançado na estrutura, que se pode chamar de resistência efetiva $(\mathrm{ACl}$ 214.4R-10, 2010). Essa resistência in loco, é necessariamente estimada a partir de um corpo normalizado. Porém, o controle tecnológico que se aplica corriqueiramente nas obras novas, é realizado de forma muito peculiar e padronizada, ou seja, se referem a corpos de prova moldados e curados por meio de condições ideais e considerando a resistência potencial como o maior valor entre as rupturas de corpos de prova irmãos. Desse modo, para extrair testemunhos e afirmar conformidade ou não do concreto, é importante conseguir converter o valor de resistência à compressão do testemunho, obtido em uma peça real com cura natural e submetido às condições de 
carregamento em serviço, em um valor equivalente ao obtido em um corpo de prova moldado nas condições normalizadas. Este é um desafio para o engenheiro envolvido na inspeção.

Para fazer isso, devem-se considerar as diferenças nas condições de cura, na idade, no grau de compactação, no diâmetro do cilindro, no fator de esbeltez, o efeito rush e os possíveis danos inerentes ao trabalho de extração. É devido à possibilidade de estabelecer uma relação da resistência desse testemunho com o de um corpo de prova cilíndrico normalizado, com esbeltez $\mathrm{h} / \mathrm{d}=2,0$, por meio de fatores de correção, que o ensaio de compressão de testemunhos de concreto tem validade (ASTM C42/ 1992).

Sendo assim, este campo de atuação é o foco deste trabalho, que visa colaborar na produção de informações, que possam contribuir para um melhor entendimento dos efeitos que devem ser considerados no ato de inspeções, que façam uso da técnica de extração de testemunhos, para interpretar a resistência à compressão do concreto extraído de peças reais em serviço.

\section{OBJETIVO}

A presente pesquisa tem como objetivo avaliar alguns dos fatores que podem influenciar o resultado dos ensaios de resistência à compressão em testemunhos extraídos de estruturas de concreto. Os fatores avaliados foram referentes à forma das amostras, ou seja, o diâmetro de extração dos testemunhos e sua esbeltez (relação altura/diâmetro). Foi avaliada também a diferença dos ensaios de resistência à compressão em amostras moldadas e extraídas.

\section{O QUÊ AFETA A RESISTÊNCIA DOS TESTEMUNHOS?}

De acordo com Helene (2011), para uma análise confiável dos testemunhos extraídos devem-se utilizar máquinas de extração adequadas e sem folga no eixo, adequadamente fixadas à estrutura, para que não trepidem durante a extração. Além disso, é aconselhado evitar a extração de mais de um testemunho por pilar. Caso seja necessária a extração no mesmo elemento, recomenda-se extraí-los na mesma face do testemunho anterior e em posição vertical.

No Brasil, a influência do tamanho dos corpos de prova sobre a resistência do concreto é normatizadda pela NBR 5738 (ABNT, 2015) e NBR 5739 (ABNT, 2007), que determinam que os corpos de prova sejam cilíndricos, podendo ter diâmetros (d) de 100, 150, 250 ou $450 \mathrm{~mm}$ e altura (h) equivalente a 2 d. Sobre trabalhos de inspeção baseadas em extração de testemunhos, a NBR 6118 (ABNT, 2014) recomenda que seja determinado $f_{c, e x t, j}$, que representa a resistência à compressão do concreto, obtida a partir de testemunhos extraídos e ensaiados, com carregamento único, instantâneo e monotônico, por meio de procedimento padronizado, em uma idade j qualquer, em geral superior aos 28 dias.

A NBR 7680-1 (ABNT, 2015) padroniza o procedimento de extração de testemunhos, estabelecendo limites de desempenho para o equipamento de extração e o diâmetro dos testemunhos, preferencialmente, acima de três vezes o diâmetro do agregado graúdo, buscando-se sempre não cortar armadura e sazonando os testemunhos em laboratório ao ar por $48 \mathrm{~h}$ antes da ruptura, sempre que a estrutura não vá estar submersa.

Um dos maiores questionamentos a este ensaio vem da definição do diâmetro do testemunho. A ASTM C 42 (1992) exige diâmetros que tenham no mínimo $95 \mathrm{~mm}$, desde que o agregado do concreto empregado tenha $D_{\text {máx }}$ inferior a 37,5 mm. Existem recomendações que indicam que os testemunhos com diâmetros menores só devem ser usados quando for impossível de se obter uma relação altura/diâmetro (h/d) superior a 1 (Concrete Society, 1976).

A Britain Stardand 1881: Part 201 (2011) recomenda a utilização de diâmetro mínimo de 100 $\mathrm{mm}$, com preferência para os de $150 \mathrm{~mm}$. A norma australiana permite o uso do diâmetro de $75 \mathrm{~mm}$ (Castro, 2009). A NBR 7680-1 (ABNT, 2015) indica que o diâmetro do testemunho cilíndrico, para a realização do ensaio normalizado pela NBR 5739 (ABNT, 2007), deve ser pelo menos três vezes 
maior que a dimensão nominal do agregado graúdo contido no concreto e preferencialmente maior ou igual a $100 \mathrm{~mm}$. Além disso, os testemunhos devem apresentar o coeficiente de esbeltez $h / d$ na faixa de $1 \geq h / d \geq 2$.

Ainda sobre o diâmetro do testemunho, Helene (2011) aponta que o ideal seria extrair testemunhos com $15 \mathrm{~cm}$ de diâmetro e $30 \mathrm{~cm}$ de altura, porém as restrições geométricas e de bom senso recomendam extrair testemunhos menores. Tokay e Ozdemir (1997) apontam que as diferenças no diâmetro, para concretos de alta resistência, são desprezíveis, outros recomendam que um estudo seja feito na obra, quando houver dúvidas substanciais ( $\mathrm{ACl}$ 214.4R-10/2010).

Helene (2011) considera que as diferenças introduzidas pela variação do diâmetro do testemunho são desprezíveis na grande maioria dos casos e não justifica estudos de correlação in situ, pois são complexos, caros e de difícil conclusão. Após analisar os coeficientes de ajuste de várias normas e recomendações, ele resume que poder-se-ia majorar de 11 a 25\%, a critério do consultor, os resultados obtidos dos testemunhos de concreto. Sempre considerando que a falha de um testemunho pode indicar uma questão local, em vez de um problema global.

Por outro lado, Bungey e Millard (1996) afirmam que o diâmetro é uma das variáveis que mais pode afetar o resultado obtido no ensaio, por isso geralmente são utilizados os de $75 \mathrm{~mm}$ ou 100 $\mathrm{mm}$. O emprego de testemunhos menores os torna mais suscetíveis aos efeitos da operação de extração, que pode afetar negativamente a zona de interface agregado/pasta (BUNGEY e MILLARD, 1996). Discrepâncias nos resultados podem ser provocadas pelo processo de extração e corte, com surgimento de microfissuras.
Quanto à variabilidade dos resultados obtidos de testemunhos de diferentes diâmetros, Lewis (1976) afirma que há maior dispersão entre as resistências dos testemunhos de $50 \mathrm{~mm}$ quando comparados aos de $100 \mathrm{~mm}$. Bungey e Millard (1996) afirmam que quanto menor o diâmetro, mais baixa é a resistência e menor a precisão de seus ensaios, o que obriga o emprego de maior número de testemunhos. Bowman (1980) aponta que os ensaios de compressão de testemunhos de $50 \mathrm{~mm}$ podem atingir um coeficiente de variação (CV) de 28,9\%, um dos motivos disso, seria o dano provocado pela extração que se torna maior quanto menor for o diâmetro. A Tabela 1 apresenta uma visão geral de fatores de conversão dos corpos de prova de diâmetro $50 \mathrm{~mm}$ para $100 \mathrm{~mm}$.

De acordo com o exposto na Tabela 1, fica evidente que o tema da relação e precisão entre a prática de extrair corpos de prova de diâmetro 50 $\mathrm{mm}$ ou $100 \mathrm{~mm}$ foi estudada por muitos autores, principalmente nos anos 60 a 80, contudo ainda não há consenso dos valores estudados. Alguns pesquisadores defendem que os corpos de prova de diâmetro de $50 \mathrm{~mm}$ apresentam maior resultado do que o de $100 \mathrm{~mm}$ e outros mostram resultados contrários.

Quanto ao processo de extração (efeito do broqueamento), Neville (2008) aponta que a microfissuração provocada, que não é considerada pela NBR 7680 (ABNT, 2015), é um dos motivos de a resistência dos testemunhos ser menor do que os corpos de prova moldados. A Tabela 2 apresenta um resumo de vários documentos e os coeficientes de ajuste indicados para a análise comparativa da resistência de corpos de prova extraídos com corpos de prova moldados.

TABELA 1: Relação da resistência obtida do extraído diâmetro 50/100 mm, segundo diferentes autores.

\begin{tabular}{c|c|c|c} 
Fonte & $\mathbf{f}_{\mathrm{c}, \mathbf{5 0}} / \mathbf{f}_{\mathrm{c}, \mathbf{1 0 0}}$ & Fonte & $\mathbf{f}_{\mathrm{c}, \mathbf{5 0}} / \mathbf{f}_{\mathrm{c}, \mathbf{1 0 0}}$ \\
\hline Petersons (1964) & 1,01 & Lewis (1976) & 1,03 \\
\hline Meininger (1968) & 1,04 & Bungey (1979) & 1,99 \\
\hline Henzel \& Freitag (1969) & 1,06 & Keiller (1984) & 0,99 \\
\hline Rechardt-Poijarvi (1969) & 0,99 & Munday \& Dhir (1984) & $0,94-0,97$ \\
\hline Sangha \& Dhir (1972) & 1,02 & Yip \& Tam (1988) & 0,94 \\
\hline De Smitter (1974) & 0,90 & Barlett \& MacGregor (1994) & 1,12 \\
\hline Bentur (1977) & 0,90 & Arioz et al. (2007) & FONTE: Adaptado de HENAO (2012).
\end{tabular}


TABELA2: Conversão da resistência obtida do extraído para o moldado, segundo diferentes normas.

\begin{tabular}{c|c}
\hline Documento de referência & Coeficiente de ajuste $\left(\mathbf{f}_{\mathrm{c}, \mathrm{j}} / \mathbf{f}_{\mathrm{c}, \mathrm{ext}, \mathrm{j}}\right)$ \\
\hline NBR 6118 (ABNT, 1980) & 1,10 ou 1,15 \\
\hline NBR 6118 (ABNT, 2003) & 1,10 \\
\hline NBR 6118 (ABNT, 2014) & 1,10 \\
\hline ACI 318/2010 & 1,25 \\
\hline ACI 437 \& EUROCODE II (1992) & 1,18 \\
\hline MODEL CODE 90 & 1,20 \\
\hline EN 13791/2007 & 1,18 \\
\hline
\end{tabular}

Segundo o relatório da CSTR11 (1987), os testemunhos extraídos na horizontal, direção perpendicular à descarga, têm resistências entre 5 a 8\% menores. A EN 13791 (2007) indica que os valores de resistência à compressão provenientes de extração perpendiculares ao lançamento é entre 0 e $8 \%$ menores do que extrações no sentido da descarga de concreto.

A NBR 7680-1 (ABNT, 2015) recomenda que se efetue a amostragem de testemunhos extraídos de concreto somente de regiões sãs e íntegras, sempre e quando o objetivo seja avaliar a resistência à compressão do concreto.

O relatório CSTR 11 (1987) indica que, para a determinação da resistência in situ num dado ponto, a taxa de erro de um único testemunho é de $\pm 12 \%$ da resistência real e assim, para $n$ testemunhos, a resistência média será de $\pm(12 / \mathrm{V}$. \%) da resistência real. O ACl 214.4R-10 (2010) também adota a taxa de erro de $\pm 12 \%$ para um testemunho, mas recomenda que sejam aplicados dois métodos para se obter a resistência equivalente final do concreto. Os dois métodos, conhecidos como Tolerance fator method e Alternative method consideram o coeficiente de variação intrínseco a resistência da estrutura e o desvio-padrão da amostra para calculo das resistências reais.

O procedimento adotado no Reino Unido é baseado em testes de testemunhos num estado saturado. Já nos EUA, o ensaio é realizado no estado seco, isso se o concreto in situ está neste estado. No Brasil, o testemunho deve ser ensaiado o mais próximo da situação de serviço na estrutura analisada. De acordo com a norma EN 13791 (2007), as amostras secas são mais resistentes do que as úmidas. Se o testemunho, pela sua localização dentro da estrutura, estiver saturado terá resistência entre 10 a 15\% menor.

Todo este panorama colocado neste item explica porque a resistência obtida a partir de testemunhos extraídos poderá ser diferente das amostras moldadas. Mesmo se fosse possível obter testemunhos perfeitamente intactos, geometricamente idênticos aos moldados; ainda assim, o adensamento e cura realizados durante $o$ lançamento na estrutura seriam diferentes dos utilizados para moldar os corpos de prova e, por consequência, suas resistências seriam distintas. $O$ valor da resistência tende a ser menor que o valor real, pois as operações de extração e ensaio, por melhor que sejam, introduzem efeitos deletérios no testemunho (efeito broqueamento) e podem reduzir sua resistência original. A qualidade desse parâmetro depende também da escolha das áreas da extração das amostras, influenciadas por regiões que podem possuir concreto mal adensado, resultando em uma possível avaliação errônea. Outros ruídos característicos deste processo decorrem da interpretação dos resultados, que dependem da qualificação e experiência do responsável técnico, de fatores de ajustes e de análises estatísticas. 


\section{MATERIAL E MÉTODOS}

Este programa experimental focou na quantificação de alguns fatores de influência na resistência do concreto, que por sua vez é medida a partir da extração de testemunhos de peças de concreto. Os fatores de influência estudados estão citados a seguir:

- Diferença de resultados de testemunhos extraídos com diâmetros de $50 \mathrm{~mm}$ e $100 \mathrm{~mm}$;

- Influência da variação do h/d nos resultados de resistência à compressão;

- Efeito da operação de extração dos testemunhos nos valores de resistência obtidos.

\subsection{MATERIAL}

Para a dosagem dos concretos foram utilizados: cimento CP II-F-32, agregados naturais, artificiais, areia industrializada e um aditivo superplastificante. O agregado graúdo utilizado possui dimensão máxima característica $\left(D_{\text {máx} .}\right)$ de $19 \mathrm{~mm}$.

Foram empregados no estudo dois traços de concreto, determinados previamente em estudo de dosagem, sendo um de menor resistência à compressão, enquadrado na NBR 8953 (ABNT, 2015) como C20 e outro de maior resistência, enquadrado como C30. A proporção utilizada nos dois concretos está apresentada na Tabela 3.

\subsection{MÉTODO}

Foram moldados dois blocos para um tipo de concreto (fck de 20 e $30 \mathrm{MPa}$ ), com dimensões iguais a: $500 \times 630 \times 270 \mathrm{~mm}$. A quantidade de blocos a serem moldados foi definida em função do número de corpos de prova extraídos e do número de idades estudadas. Os dois blocos foram moldados com o mesmo traço, porém em betonadas diferentes. Os blocos 1 e 2 representaram o concreto de $20 \mathrm{MPa}$ e os blocos 3 e 4 representaram o concreto de $30 \mathrm{MPa}$.

No momento da confecção dos blocos foram também moldados corpos de prova cilíndricos de $100 \mathrm{~mm} \times 200 \mathrm{~mm}$. Isto foi feito para a determinação da resistência à compressão aos 28 e aos 63 dias (momento da extração e ruptura dos testemunhos). A idade de 63 dias foi escolhida por representar um estágio avançado de hidratação, simulando uma estrutura antiga e inspecionada depois de décadas em operação, o que é comum em trabalhos que geram a necessidade de verificação de resistência do concreto. Os 63 dias foram adotado por ser um valor múltiplo de 7 e garantir que o ensaio fosse feito durante a semana.

Ao todo foram moldados quatro corpos de prova cilíndricos, sendo dois para cada traço (forte e fraco) e um para cada idade (28 e 63 dias).

As extrações dos testemunhos dos blocos foram feitas todas na vertical, isto é, na mesma direção de lançamento do concreto, e o procedimento seguiu as preconizações da NBR 7680-1 (ABNT, 2015).

TABELA 3: Proporcionamento dos materiais empregados para os concretos $\mathrm{C} 20$ e C30.

\begin{tabular}{c|c|c}
\hline Material (kg) & C20 & C30 \\
\hline Cimento & 1,00 & 1,00 \\
\hline Areia natural & 1,12 & 1,11 \\
\hline Areia artificial & 2,71 & 1,57 \\
\hline Brita 1 & 3,00 & 2,04 \\
\hline Brita 2 & 1,00 & 0,68 \\
\hline Água & 0,70 & 0,48 \\
\hline Resistência à compressão aos 28 dias & $1,0 \%$ & $1,0 \%$ \\
\hline
\end{tabular}


Os testemunhos tiveram seus topos regularizados por meio de retificação com serra metálica diamantada e capeados com pasta de enxofre (NBR 5738 - ABNT, 2015), obtendo-se faces planas, paralelas e normais ao seu eixo vertical, normalizados para os ensaios de ruptura.

Para estudo da influência da esbeltez foram extraídos testemunhos, com dimensões diâmetro/altura de $100 \times 200 \mathrm{~mm} \quad(\mathrm{~h} / \mathrm{d}=2)$, $50 \times 150 \mathrm{~mm} \quad(\mathrm{~h} / \mathrm{d}=3), 50 \times 100 \mathrm{~mm} \quad(\mathrm{~h} / \mathrm{d}=2)$, $50 \times 75 \mathrm{~mm}(\mathrm{~h} / \mathrm{d}=1,5)$ e $50 \times 50 \mathrm{~mm}(\mathrm{~h} / \mathrm{d}=1)$.

Já para a análise da interferência do diâmetro de extração, foram adotados dois valores, $50 \mathrm{~mm}$ e $100 \mathrm{~mm}$. Por fim, para o estudo comparativo com os corpos de prova moldados, foram também extraídas peças cilíndricas de $100 \mathrm{~mm} \times 200 \mathrm{~mm}$.

Em todos os casos, os ensaios para a determinação da resistência à compressão seguiram as recomendações da NBR 5739 (ABNT, 2007).

Tanto os blocos, como os corpos de prova moldados, ficaram em cura até o momento da extração e ruptura dos corpos de prova, de modo que o método de cura neste estudo não foi uma variável entre os blocos e os corpos de prova moldados. A cura foi realizada em câmara úmida com U.R. de $100 \%$ e temperatura controlada em $22^{\circ} \mathrm{C}$.

A padronização da cura foi realizada para que, no momento de avaliação das diferenças existentes entre os resultados dos corpos de prova moldados e os testemunhos, esta não seja uma fonte de variação, de modo que a diferença obtida seja apenas relativa à prática de extração do corpo de prova.

O critério adotado para a análise dos resultados de resistência foi o da resistência potencial, ou seja, para cada caso foram extraídos dos testemunhos e o maior valor foi o adotado.

\section{RESULTADOS DE RESISTÊNCIA À COMPRESSÃO AXIAL}

\subsection{INFLUÊNCIA DO FATOR DE ESBELTEZ h/d/}

Como mencionado anteriormente, a teoria indica que, considerando o mesmo concreto a ser ensaiado, quanto menor o fator de esbeltez $(\mathrm{h} / \mathrm{d})$, maior o resultado de resistência à compressão. Contudo, nesta pesquisa, isso não foi comprovado, como pode ser observado na Figura 1.

Nota-se que, no caso do concreto de $f_{c k}$ igual a $20 \mathrm{MPa}$, os resultados não sofreram influência do fator de esbeltez. Quando existiu um indício de influência foi no caso do $\mathrm{h} / \mathrm{d}$ igual a 3 para o bloco 2 , porém a influência foi contrária a esperada, com a resistência sendo maior do que a apresentada para o fator de esbeltez igual a 2 .

No caso do $f_{c k}$ igual a $30 \mathrm{MPa}$, de modo geral, também não pareceu existir efeito do fator de esbeltez. Apenas no caso do bloco 4 e fator de esbeltez igual a 3, ocorreu um comportamento semelhante ao encontrado no bloco 2 , com o valor de resistência à compressão sendo maior do que no caso de $h / d$ igual a 2 .

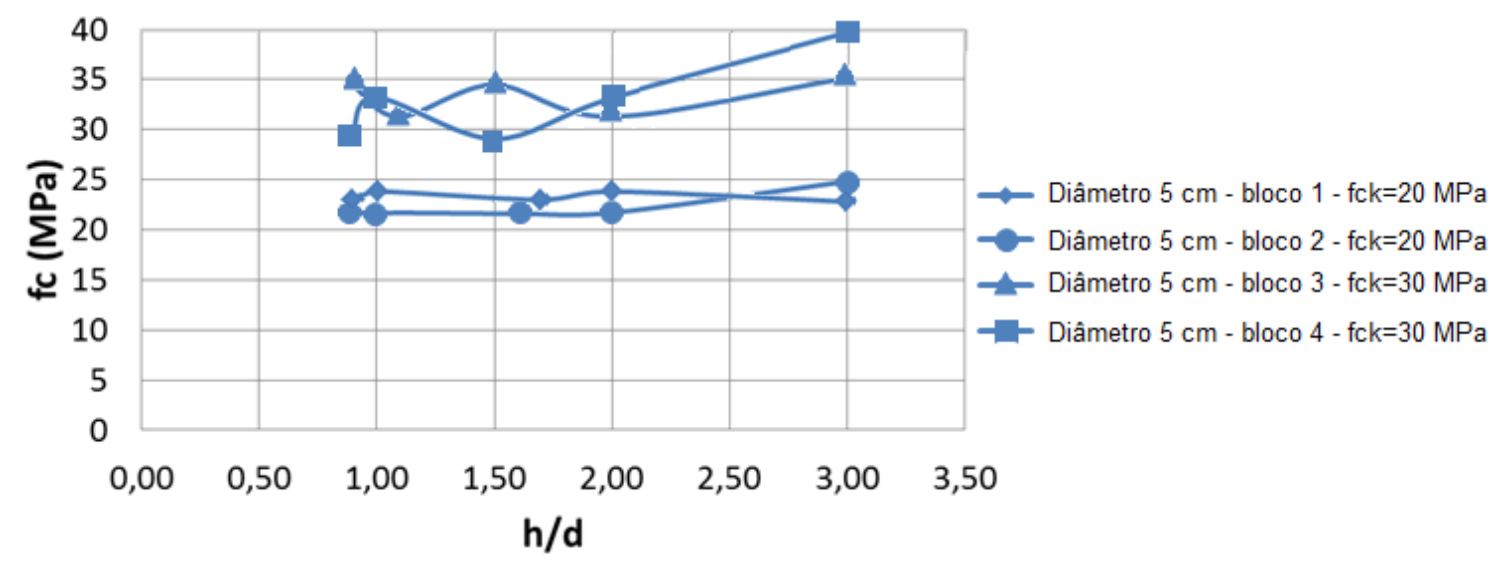

FIGURA 1: Influência do fator de esbeltez para concreto de $20 \mathrm{MPa}$ (bloco 1 e 2) e $30 \mathrm{MPa}$ (bloco 3 e 4). FONTE: Autoria própria. 
Desse modo, os resultados apresentados não confirmam a influência do fator de esbeltez do testemunho extraído, para os serviços de determinação da resistência do concreto em trabalhos de campo.

\subsection{INFLUÊNCIA DO DIÂMETRO DO TESTEMUNHO}

É consensual, entre os pesquisadores, que as diferenças encontradas em amostras com diâmetros de 100 mm e 150 mm são insignificantes (CSTR 11, 1987), o mesmo não ocorre quando se avaliam amostras de $50 \mathrm{~mm}$ e os de $100 \mathrm{~mm}$ (ACl 214.4R-10/2010). Alguns pesquisadores indicam que a resistência aumenta à medida que o diâmetro do testemunho diminui (NEVILLE, 2008). Neste estudo, os resultados não apontaram este fato. Não houve diferenças significativas entre os resultados dos diâmetros 50 e 100 mm, sugerindo a viabilidade de sua utilização do diâmetro menor, que por vezes, se torna mais adequado às necessidades da estrutura que se pretenda avaliar. Os resultados desta pesquisa estão representados nas Figuras 2 e 3 , e foram desenvolvidas para concreto de $\mathrm{f}_{\mathrm{ck}} 20 \mathrm{MPa}$ e 30 Mpa, respectivamente. Analisando os concreto de $f_{c k}$ igual a $20 \mathrm{Mpa}$ (Figura 2) com base no fator $\mathrm{f}_{c, 50} / \mathrm{f}_{\mathrm{c}, 100}$, verifica-se que para o primeiro bloco o fator foi de 0,95 e para o segundo foi de 1,00.

Fazendo a mesma análise para o concreto de $f_{c k}$ igual a $30 \mathrm{Mpa}$, o fator $\mathrm{f}_{\mathrm{c}, 50} / \mathrm{f}_{\mathrm{c}, 100}$ foi igual a 0,85 para o bloco 3 e 0,87 para o bloco 4 . Isso leva a crer que o nível de resistência do concreto influi no fator de conversão $f_{c, 50} / f_{c, 100}$, fato que não foi relatado por nenhum dos trabalhos citados na Tabela 3.

A BS EM 12504-1 (2009) corrobora estes resultados, pois aponta em seu Anexo A, que, para agregados com $D_{\text {máx }}$ de $20 \mathrm{~mm}$, os testemunhos de $100 \mathrm{~mm}$ são aproximadamente $7 \%$ mais resistentes que os de $50 \mathrm{~mm}$.

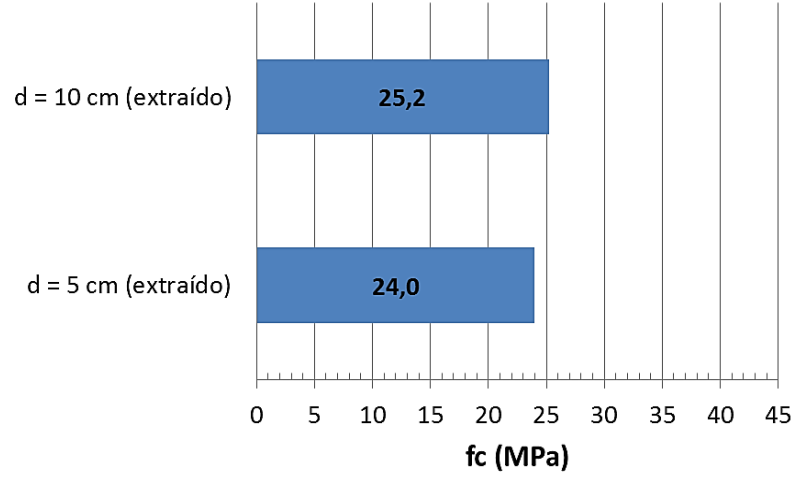

[a]

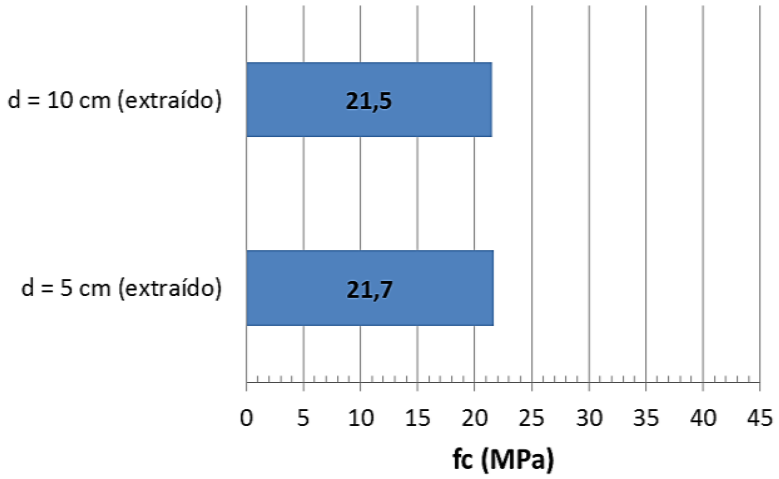

[b]

FIGURA 2: Influência do diâmetro do testemunho para concreto de $f_{c k}=20 \mathrm{MPa}$. [a] bloco 1: $h / d=2$. [b] bloco 2: $h / d=2$.

FONTE: Autoria própria.

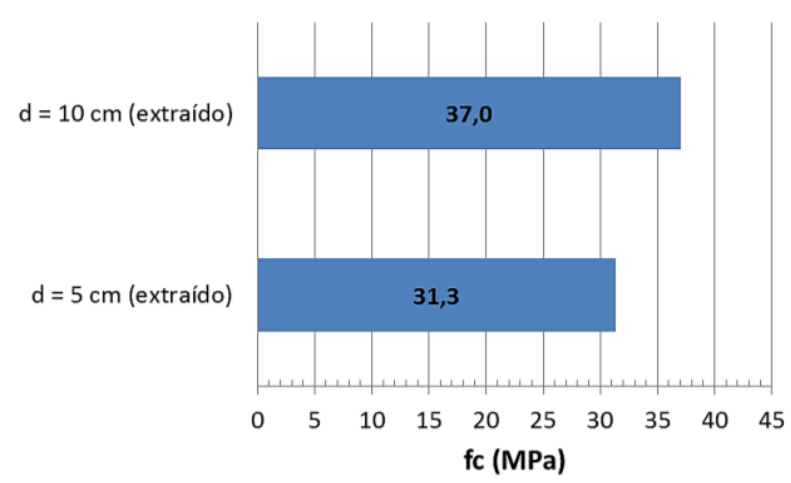

[a]

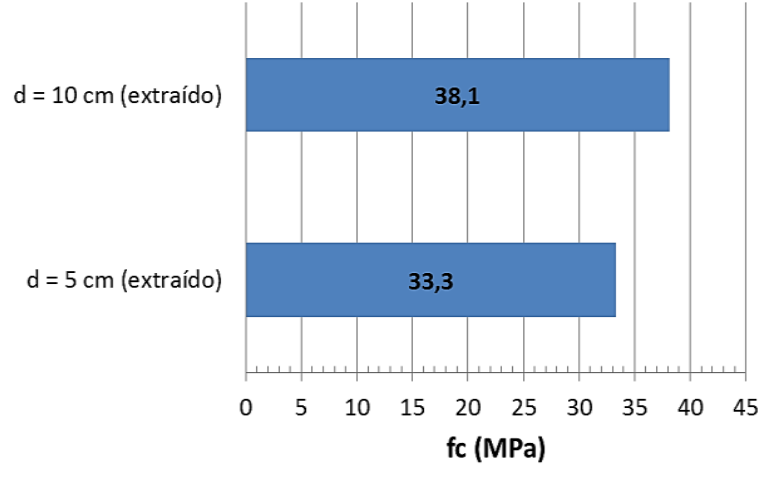

[b]

FIGURA 3: Influência do diâmetro do testemunho para concreto de $f_{c k}=30 \mathrm{MPa}$ [a] bloco 3: $h / d=2$. [b] bloco 4: $h / d=2$.

FONTE: Autoria própria. 


\subsection{INFLUÊNCIA DA EXTRAÇÃO DOS TESTEMUNHOS}

Pelo que foi exposto anteriormente, não se pode obter, da compressão axial de testemunhos, uma medida direta da resistência do concreto da estrutura e a de um corpo de prova normalizado, pois não há relação universal entre elas.

As Figuras 4 e 5 ilustram esta questão, de que os corpos de prova extraídos apresentam valores de resistência à compressão inferior aos corpos de prova moldados. Analisando comparativamente os coeficientes de ajuste da Tabela $2\left(f_{c, j} / f_{c, e x t, j}\right)$, obteve-se neste estudo, para o concreto de $20 \mathrm{MPa}$, o bloco 1 e bloco 2, valores de 1,11 e 1,29, respectivamente. Para o concreto de $30 \mathrm{MPa}$, o bloco 3 e 4, apresentaram valores de
1,20 e 1,00, respectivamente. Desse modo, corroborando com a informações existentes no meio técnico, os valores de resistência à compressão, obtidos a partir de testemunhos extraídos, devem mesmo ser majorados para poderem ser usados como referência ao concreto em obra.

Como estes resultados se referem a condições de cura padronizadas, entre os blocos e corpos de prova moldados, é provável que o efeito da cura gere índices $f_{c, j} / f_{c, \text { ext,j }}$ ainda maiores em condições reais de campo, uma vez que a cura dos corpos de prova moldados é próxima da ideal e a do testemunho é a cura adotada de forma corriqueira em obras que pode ser deste ausência de cura a uma cura deficiente durante poucos dias.

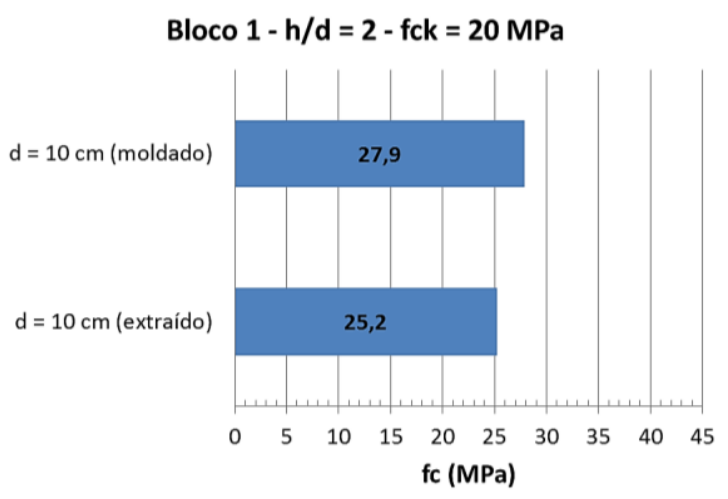

[a]

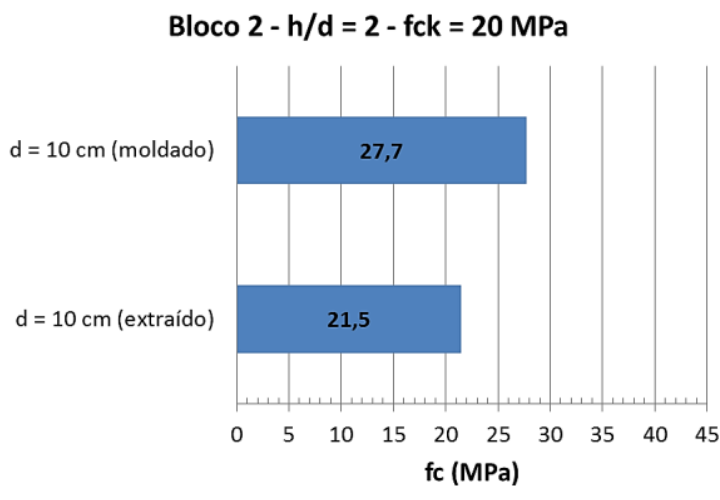

[b]

FIGURA 4: Comparação do testemunho extraído com o controle com corpos de prova moldados $\left(f_{c k}=20 \mathrm{MPa}\right)[\mathrm{a}]$ bloco $1: \mathrm{h} / \mathrm{d}=2[\mathrm{~b}]$ bloco $2: \mathrm{h} / \mathrm{d}=2$.

FONTE: Autoria própria.

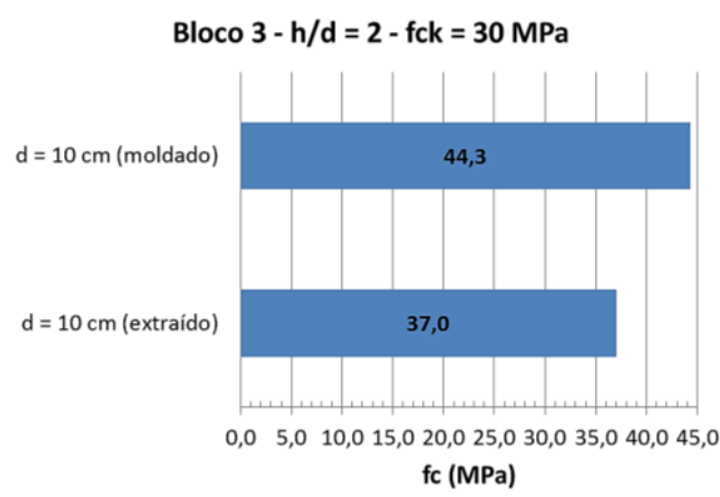

[a]

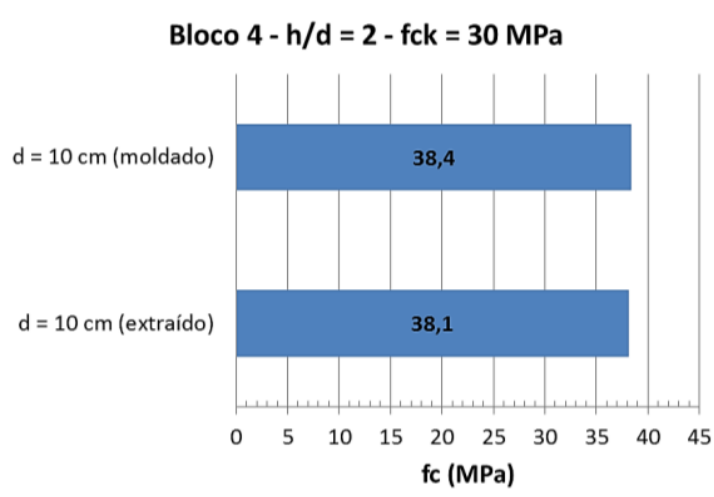

[b]

FIGURA 5: Comparação do testemunho extraído com o controle com corpos de prova moldados $\left(f_{c k}=30 \mathrm{MPa}\right)[\mathrm{a}]$ bloco $3: \mathrm{h} / \mathrm{d}=2$ [b] bloco 4: $h / d=2$.

FONTE: Autoria própria. 


\section{CONCLUSÕES}

Este trabalho verificou algumas constatações importantes na área de uso de testemunhos extraídos para determinação da resistência à compressão de estruturas de concreto em serviço. São elas:

- Os resultados obtidos em testemunhos de $5 \mathrm{~cm}$ de diâmetros tenderam a ser iguais ou inferiores aos obtidos nos testemunhos de $10 \mathrm{~cm}$ de diâmetro. As diferenças nos resultados parecem ser mais relevantes para o concreto de $f_{c k}$ igual a $30 \mathrm{MPa}$ do que o de $20 \mathrm{MPa}$, indicando uma influência do nível de resistência do concreto que está recebendo o trabalho de extração;

- O fator de esbeltez h/d não apresentou tendência clara de efeito nos resultados obtidos. A teoria indica que quanto maior o $\mathrm{h} / \mathrm{d}$, menor a resistência do testemunho, porém, os dados obtidos ou indicam nenhuma influência, ou mostram efeito inverso ao esperado;

- Considerando como o resultado final dos testemunhos de cada bloco somente o maior valor e comparando esse valor com o resultado da resistência do corpo de prova moldado a uma mesma idade j, não houve discrepância maior que 30\% entre os resultados;

- A extração do testemunho realmente resultou em resultados de resistência inferiores aos dos corpos de prova moldados, apesar de em alguns casos a diferença ser considerada desprezível;

- Dentre as possíveis variáveis da extração, o diâmetro foi um fator que demonstrou influência significativa na propriedade do material ensaiado.

\section{REFERÊNCIAS BIBLIOGRÁFICAS}

AMERICAN CONCRETE INSTITUTE. Guide for obtaining cores and interpreting compressive strength results. Reported by ACI Committee 214.4 R-10. 2010.

Building code requirements for structural concrete. Reported by ACl Committee 318 M-08. 2010.
Strength Evaluation of Existing Concrete Buildings. Reported by ACI Committee 437. 2012.

AMERICAN SOCIETY FOR TESTING AND MATERIALS. Standard test method for obtaining and testing drilled cores and sawed beams of concrete - C 42-90. In: Annual Book of ASTM Standards. Philadelphia, 1992.

ASSOCIAÇÃO BRASILEIRA DE NORMAS TÉCNICAS, NBR 5738 - Moldagem e cura de corpo-de-prova de concreto - Procedimento. Rio de Janeiro, 2015.

NBR 5739 - Ensaio de compressão de corposde-prova cilíndricos ou prismáticos de concreto Procedimento. Rio de Janeiro, 2007.

NBR 6118 - Projeto de estruturas de concreto Procedimento. Rio de Janeiro, 2014.

NBR 7680 - Extração, preparo, ensaio e análise de testemunhos de estruturas de concreto Procedimento. Rio de Janeiro, 2015.

NBR 8953 - Concreto para fins estruturais Classificação pela massa específica, por grupos de resistência e consistência. Rio de Janeiro, 2015

NBR 12655 - Concreto de Cimento Portland Preparo, controle e recebimento - Procedimento. Rio de Janeiro, 2015.

BOWMAN, S. A. W., 1980. Discussion on ref. 71. Concrete Research, 32, No 111. June, pp 124.

British Standards Institution. BS EN 1881-122 - Testing concrete. Method for determination of water absorption. London, 2011.

BS 6089. Assesment of in-situ compressive strength in structures and precast concrete components Complementary guidance to that given in BS EN 13791. London, 2010.

BS EN 12504-1. Testing concrete in structures. Cored specimens. Taking, examining and testing in compression. London, 2009.

BS EN 13791 - Assessment of in-situ compressive strength in structures and precast concrete components. London, 2007.

BUNGEY J. MILLARD, S. Testing of concrete in structures. 3. ed. London: Blackie Academic \& Professional, 1996.

CASTRO, E. Estudo da resistência à compressão do concreto por meio de testemunhos de pequeno diâmetro e esclerometria. Dissertação de mestrado apresentada a Universidade federal de Uberlândia. Uberlândia, 2009.

Comite Euro-International Du Beton - CEB-FIP Model Code 90 - Design code. (1993) 
CONCRETE SOCIETY TECHNICAL REPORT (CRTR). Concrete core testing for strength. Reported by Report №11, 1987.

EUROPEAN STANDARD - EUROCODE II. Design of concrete structures - Part 1-1: General rules and rules for buildings. 1992.

HELENE, P. R. L. Avaliação da resistência à compressão de estruturas através de testemunhos cilíndricos de concreto. III Simpósio sobre normatização de cimento, concreto e agregados. São Paulo, 1984.

HELENE, P. R. L. Análise da Resistência à Compressão do Concreto em Estruturas Acabadas com Vistas à Revisão da Segurança. Revista ALCONPAT n.1. 2011.

HENAO, Lina M. R. Ensayos de informacion y extraccion de probetas testigo en hormigones autocompactantes. Tesis Doctoral. Universidad de Medellin, Colombia. Madrid, 2012.

HOPPE FILHO, J. ; RHEINHEIMER, B. ; KHOE, S. ; ARTIGAS, L. V. ; SABBAG, A. F. ; MEDEIROS, M. H. F. . Degradação do concreto de uma Estação de Tratamento de Esgoto (ETE) por ácido sulfúrico biogênico. Revista ALCONPAT, v. 4, p. 87-99, 2014.

LEWIS, R. K. 1976. Effect of core diameter on the observed strenght of concrete cores. Research Report No. 50. CSIRO Division of Building Research, Melbourne, $13 p p$.

NEVILLE, A.M. Properties of Concrete. Fourth and final edition, Prentice hall, London, 2008, 269-592.

MEDEIROS, M. H. F. ; GOBBI, A. ; RÉUS, G. C. ; HELENE, Paulo. Reinforced concrete in marine environment: Effect of wetting and drying cycles, height and positioning in relation to the sea shore. Construction \& Building Materials, v. 44, p. 452-457, 2013.

TOKAY, M; OZDEMIR, M. Speciment shape and size effect on the compressive strength of higher strength concrete. Cement and Concree Research, vol 27, n.8. pp. 1281-1289, 1997.

VIEIRA FILHO, J. O. Avaliação da resistência à compressão do concreto através de testemunhos extraídos: contribuição à estimativa do coeficiente de correção devido aos efeitos do broqueamento. Tese apresentada à Escola Politécnica da Universidade de São Paulo. São Paulo, 2007. 